\title{
EL EMPERADOR TRAJANO COMO MODELO DE PRÍNCIPES EN LA EDAD MEDIA \\ (EL PRÍNCIPE EN “POLICRATICUS")
}

\author{
Miguel ÁNGEl LADERo QUESADA \\ Universidad Complutense de Madrid
}

\section{SUMARIO}

1. Trajano en Policraticus y en la Primera Cronica General.- 2. El Príncipe en Policraticus.

De los modelos políticos y militares de la Antigüedad, el más admirado y citado en la Edad Media fue, sin duda, Alejandro Magno, en su condición de guerrero y conquistador tanto o más que en la de gobernante. También lo fue, aunque en menor medida, Trajano pero, en este caso, por las virtudes políticas que se le atribuían, no sólo por las guerreras, que también las tuvo, y por la benevolencia que, según se creía, manifestó hacia los cristianos, al suspender la persecución a muerte contra ellos. Fue precisamente este aspecto el que le libró de las penas del infierno, según el relato de Juan Diácono, que muestra cómo el papa Gregorio I, al ensalzar su virtudes y rogar por él, con abudantes lágrimas, acabó consiguiendo - según revelación que tuvo- que el pagano emperador engrosara el número de los bienaventurados, a condición, eso sí, de que el papa "en adelante no pidiese a Dios por ningún infiel"!

\footnotetext{
'Juan DiÁcono, Sancti Gregorii Magni Vita II,44 (Mıgne, Patrologia Latina, 75, 104-106). Recoge la leyenda Juan de SAlISBURY, Policraticus, Libro IV, Cap. 8: sigo la edición de Madrid, 1984, de la que fuí coordinador e introductor, con excelente traducción al español de un equipo coordinado por Matías García Gómez y Tomás Zamarriego, a partir de la edición de

"Anuario de Lstudios Medievales". 29 (1999)
} 


\section{TRAJANO EN "POLICRATICUS" Y EN la "Primera Crónica General"}

La fama de Trajano se difundió especialmente desde mediados del siglo XII gracias a la atención que le dedicó Juan de Salisbury en su Policraticus -concluído en 1159-, aunque está por hacer un inventario de referencias sobre el emperador en autores y textos medievales. Toda la parte central de Policraticus los libros cuarto, quinto y sexto, es un amplio 'espejo de príncipes', el más extenso y completo de los escritos hasta entonces, y, en él, la figura de Trajano juega un papel importante, como modelo e inspirador.

El autor explica las razones de esta predilección especialmente en un breve capítulo titulado "por qué parece que Trajano debe ser preferido a todos los demás", en el que ensalza, ante todo, su capacidad política y militar: "fue de tanta fortaleza y calidad política, que amplió considerablemente en todos los sentidos los límites del Imperio romano, que, después de Augusto, había sido más bien defendido que ampliado". Pero importaron más aún sus cualidades como gobernante: prudencia, gobierno justo, afable, enriquecedor de todos, igual "con Roma que con todas las provincias", de modo que "fundamentó la grandeza de su reinado exclusivamente en el culto a la virtud". "Fue por naturaleza clemente con todos y duro con los pocos a quienes perdonar sería un crimen ... pues solía decir que estaba loco el que ante una inflamación de los ojos prefería arrancárselos a curarlos". Así, "su recuerdo nos ha sido transmitido en tales términos y su fama ha llegado a tanto, que proporciona tanto a los amigos que realmente alaban como a los aduladores, el más excelso ejemplo para las comparaciones"2.

No fue Juan de Salisbury el único autor en apelar al recuerdo y ejemplo político de Trajano pues en semejantes términos lo hace la Primera Crónica General de Alfonso X de Castilla, escrita más de cien años después, utilizando la misma fuente que Policraticus, o bien a esta misma obra, pues la traducción parece a menudo literal, salvando la frescura introducida por el romance castellano en su recién estrenado uso literario.

\section{C.C.J. Webb (Oxford, 1909).}

${ }^{2}$ Policraticus, V,8 y IV, 8 
Así, en el mismo capítulo que acabamos de citar, Juan de Salisbury recoge la anécdota o ejemplo de cómo Trajano, conmovido ante las súplicas de una viuda cuyo hijo había sido muerto inícuamente, aplazó otras cuestiones más importantes para hacerle justicia, a pesar de lo inoportuno del momento. Dión Casio, de quien procede la anécdota, quería significar con ella cómo el príncipe debe hacer justicia rápida y sencilla al pueblo, antes y primero que cualquier otra obligación tocante a su gobierno. He aquí la versión de la Primera Crónica General ${ }^{3}$ :

A est emperador Traiano auino una uez que yua a una batalla, et subio en su cauallo, et en saliendo en el de su palacio, parossele delante una bibda; et trauol del pie llorando muy de rezio, et pidiol mercet quel fiziesse derecho dunos omnes quel mataran su fijo a tuerto, que nunqua fiziera mal a ninguno nin gelo buscara, et diziel: "Tu, Augusto, seyendo emperador, suffro yo tan esquiuo tuerto cuemo aqueste!". E dixol Traiano: "Yo te dare derecho tanto que torne de la batalla". E ella respondiol: "et si no tornares, ique sera de mi ?". El dixol: "el que fuere emperador despos mi te lo emendara”. E dixo entonce la bibda: “¿cuemo sere yo cierta desso ?, et pongamos que sea assi ; ique prouecho de aura a ti el bien que otri fiziere ?, ca tu eres mi debdor et as a auer gualardon segund lo merecieres. Enganno faras si me no dieres lo que me deues. E ell emperador que uinier despos ti, por si sera tenudo de fazer iusticia a los querellosos, et a ti no te librara el derecho ageno, ca bien sera del tu heredero si liurare assi mismo". E Traiano, que oyo aquesto, mouiossele el coraçon et ouo duelo de la bibda, et dicio del cauallo, et oyo el por si mismo todo el pleyto, et diol luego tal derecho qual conuinie.

Del mismo modo, tanto Policraticus como la Primera Crónica recogen otros dichos del emperador, tendentes a mostrar su sencillez de trato, en lo que manifestaba la justa combinación entre amor y disciplina en las relaciones del príncipe con sus sujetos:

${ }^{3}$ Primera Crónica General de España, edic. R. MEnÉndez PIDAL, Madrid, Gredos, 1955, vol. 1,192, pp. 142 a 145 (PCG, en lo sucesivo). Lógicamente, la Crónica manifesta un interés añadido, dada la condición hispánica del emperador: "este Traiano fue espannol, cuemo dessuso es dicho, et natural duna uilla de Estremadura que a nombre Pedraza (cerca de Segovia), e dixieronle Traiano por que era del linage de Troya que uinieron poblar aquella tierra, ca el Vlpio Crinito auie nombre, et por sobrenombre Traiano". Es interesante observar como la PCG sitúa el nacimiento de Trajano todavía en Pedraza y no en Italica, como luego fue común. La alabanza de Trajano y, con variantes, los ruegos de Gregorio I por su salvación, que mencionamos en el texto, se recogen tambien en PCG. 


\begin{abstract}
Trajano, el mejor de los emperadores paganos, respondió magníficamente a unos amigos que le reprochaban que era excesivamente llano con todos, mucho más de lo que convenía a un emperador, que él quería ser para los ciudadanos privados la clase de emperador que él mismo había deseado que fueran los emperadores para con él cuando era un simple ciudadano (Policraticus, IV,8)

E entre muchas buenas palauras que Traiano dixo, cuentan del las estorias que por que era tan bueno et $\tan$ mesurado et $\tan$ compannero de los omnes, et los affazie tan mucho assí, quel preguntaron un dia sus priuados et sus amigos por que lo fazie ; et el dixoles que tal emperador querie el seer a los que no auien dignidades ni sennorios, quales solie el querer, al tiempo que las no auie, quel fuessen los otros emperadores (PCG, epígr. 192, I, p. 143).
\end{abstract}

Otro episodio, el del castigo a que sometió Plutarco a un esclavo suyo y el diálogo que entre ambos pasó sobre la serenidad en la aplicación de las penas, que también recoge Juan de Salísbury, tiene su correspondiente versión castellana. idéntica, en la Crónica ${ }^{5}$. Hasta aquí, las citas sobre Trajano proceden de autores y fuentes conocidas, pero el problema principal surge cuando llegamos al nudo expositivo de Policraticus en su condición de 'espejo de príncipes', porque Juan de Salisbury dice inspirarse en un tratado denominado Institutio Traiani, que Plutarco habría escrito para la instrucción política de Trajano Sin embargo, la supuesta Institutio Traiani es totalmente desconocida, salvo por la cita de nuestro autor, del mismo modo que otra, que también atribuye a Plutarco pero que sólo menciona una vez, el Archigramaton ${ }^{6}$.

La mayoría de los especialistas en la obra de Juan de Salisbury han supuesto que la Institutio es una ficción, un recurso del autor para amparar sus propias opiniones bajo el amparo y el prestigio de Plutarco, del mismo modo que apela a otras muchas autoridades bíblicas y clásicas a lo largo de Policraticus. Esto es lo que opina un conocedor tan profundo de nuestro autor como Hans Liebeschütz:

${ }^{4}$ En términos semejantes lo narraba ya Lucas de Tuy (vid. la edición en romance de su Crónica de España, Madrid, 1926, cap. XXIII, p. 125). La fuente es el Breviarium de Eutropio. ${ }^{5}$ Policraticus, IV ,8, pp. 332-333. PGC, epígr. 192, pp. 142-143. La fuente es, en este caso, Gelio.

${ }^{6}$ Policraticus, IV,8. 


\begin{abstract}
Los tres libros centrales de 'Policrạticus', que tratan directamente de la administración del país, se basan en dos autoridades de diferente tipo: el comentario al 'Deuteronomio' XVII en el Libro IV va seguido en los Libros V y VI por reglas y consejos que pretenden representar el espíritu clásico del período de apogeo del Imperio Romano. Al utilizar este crisol o mezcla, Juan consiguió para su obra una objetividad de estilo superior al procedimiento habitual consistente en acumular citas de autoridades para cada tesis expuesta. El dualismo de fuentes bíblicas y clásicas es fruto de un plan. Creo que ha sido probado que la 'Institutio Traiani' citada en el 'Policraticus' es una ficción utilizada por Juan para camuflar el carácter personal de su crítica política, endosándola a una autoridad clásica ${ }^{7}$.
\end{abstract}

Sin embargo, la pregunta que inevitablemente surge es por qué Juan de Salisbury, tan cuidadoso en sus fuentes y respetuoso con ellas se habría atrevido nada menos que a inventar una obra ficticia para dar mayor fundamento a la parte central de su escrito. Podría suceder que haya existido realmente una obra conocida como Institutio Traiani y atribuída falsamente a Plutarco, que habría circulado en los medios intelectuales europeos de los siglos XII y XIII, aunque ningún manuscrito haya llegado a nuestro conocimiento. No sería el único caso de escritos elaborados en época medieval atribuídos a sabios clásicos de gran fama y autoridad: un ejemplo muy conocido son las enseñazas o castigos que, supuestamente, habría escrito Aristóteles para instrucción política de Alejandro ${ }^{8}$. De nuevo, una comparación entre Policraticus y la Primera Crónica General deja abierta la posibilidad de suponer que existió la Institutio Traiani, porque la Crónica también la menciona expresamente:

E sabet que ouo Traiano por ayo et por maestro un gran philosopho que auie nombre Plutarco, quel castigaba yl mostrava por palaura et por libros quel fazie todas buenas costumbres porque mantouiesse bien ell imperio ...E este Plutarco fizo a Traiano ell emperador un libro muy noble dell ensennamiento de las buenas costumbres en que muestra qual deue seer todo sennor, e la rubrica es tal: "Este es ell ensennamiento de Traiano" ; et el libro comiença desta guisa: "De mi, Plutarco, a ti, Traiano, salud. Bien

${ }^{7} \mathrm{H}$. LIEBESCHÜTZ, Mediev'al humanism in the life and writing of John of Salisbury, Londres, 1950, pp. 24-25. Desarrolla sus argumentos probatorios en, John of Salisbury and Pseudoplutarch, Journal of the Warburg and Courtauld Institutes, VI (1943), pp. 33-39.

${ }^{8}$ J.L. Bermejo Cabrero, Máximas, principios y símbolos políicos, Madrid, 1986, pp. 85 104, sobre el uso de los castigos de Aristóteles por autores españoles de los siglos XIII a XVII. 
sabía yo en cuemo tu eres mesurado, que no auies cobdicia de seer emperador, pero siempre lo mereciste con grand nobleza de costumbres ; et quanto menos lo cobdicieste, tanto mas digno eres de lo auer. E so yo much alegre por la tu bondat et por la mi buena uentura, solamientre que mantengas con derecho lo que mereciste con bien. E si otra guisa fizieres, diran las gentes mucho mal de ti et de mi: de ti, por que Roma non quier soffrir las maldades de los emperadores : de mi, porque es cosa much usada en los pueblos de maldezir los maestros por las maldades de los diciplos ; ca assi dizen agora de Seneca porque fue malo Nero, su diciplo, e de Quintiliano por la locura de sus criados, e a Socrates maltraen por que fue muy piadoso a un su fijo que era huerphano de madre. Mas tu bien et derechamientre puedes fazer todo lo que quisieres, tanto que no desampares a ti mismo ni te mudes de qual agora eres; ca si a ti compusieres de buenas costumbres, derechamientre faras todas las otras cosas. Sepas que te fiz aqueste libro en que te escreui todas las buenas costumbres del ensennamiento de los mayores que fueron ante de nos ; e si bien metieres y mientes, siempre auras uiuo a Plutarco que te castigue ; e si dotra guisa fizieres, este mio libro do yo por prueua que no destroiras ell imperio por conseio de Plutarcho"?

Ahora bien, esta carta de Plutarco a Trajano que, según la Crónica, inicia el libro titulado Este es el ensennamiento de Traiano traduce fielmente la epístola que Juan de Salisbury transcribe como preámbulo de la Institutio Traiani. En consecuencia, o bien la Crónica sigue a Policraticus en estas cuestiones, o bien utiliza la misma obra que Juan de Salisbury ${ }^{10}$. La primera hipótesis cuenta con mayores posibilidades, a la vista de la literalidad con que la versión castellana sigue a la latina en los ejemplos que hemos considerado, pues varios provienen de diversos autores que nada

\footnotetext{
${ }^{9}$ PCG. epígr. 192, p. 143.

${ }^{10} \mathrm{No}$ he encontrado referencia a que se haya considerado hasta ahora a Juan de Salisbury como uno de los autores utilizados para escribir la Primera Crónica General. Cfr. en especial. D. Catalán, La 'Estoria de España' de Alfonso X : creación y' evolución, Madrid, 1992, I. FERNÁNDEZ ORDÓÑEZ, La Estoria de España, la General estoria y los diferentes criterios compilatorios, "Revista de Literatura", 50 (1988), pp. 15-35. Las 'Estorias' de Alfonso el Sabio, Madrid, 1992, y, Versión crítica de la 'Estoria de España', Madrid, 1993. P. LINEHAN, From Chronicle to History: Concerning the Estoria de España and its Principal Sources, en Historical Literature in Medieval Iberia, de Alan DEYERMOND, Londres, 1996, pp. 7-33. G. MARTIN "Alphonse X et le pouvoir historiographique", en L'histoire et les nouveaux publics dan. l'Europe médiévale (XIIIe-XVe siècles), edic. J.Ph. GENET, Paris, 1997, pp. 229-245.
} 
tienen que ver con la supuesta Institutio de Plutarco. Pero la segunda no es desdeñable: al menos, se debe dejar abierta la cuestión ${ }^{\prime \prime}$.

Afirma Juan de Salisbury al comenzar el Libro Quinto de Policraticus que prefiere seguir más la línea de las ideas que la literalidad de las palabras de Plutarco, cuya obra toma como guía. Las menciones expresas a la Institutio son, efectivamente, pocas pero aparecen en momentos clave: de ella se toma la imagen de la comunidad política como un cuerpo cada una de cuyas partes cumple funciones específicas (V,2 y 17 . VI, preámbulo. VI,25, sobre la jerarquía de los miembros), la definición de los elementos básicos de la educación del príncipe $(\mathrm{V}, 3$ y 4), e incluso se afirma que Plutarco dedicó la Institutio a Virgilio, "el más docto de los poetas", sin duda por el elogio que éste hace de la ordenada vida y costumbres de las abejas, modelo para la sociedad humana bien jerarquizada. Tampoco son muchas las alusiones expresas a Trajano, y ya las hemos traído a colación: las que se contienen en IV.8 son anteriores a la primera mención de la Institutio por Juan de Salisbury y nada tienen que ver con ella, como tampoco las contenidas en V.8 (porqué Trajano debe ser preferido a todos los demás), cuando ya se ha entrado de lleno a exponer la Institutio.

Es probable, en conclusión, que nuestro autor haya manejado un texto en el que se describiera la organización política de la sociedad apelando al símil del cuerpo humano y sus partes y lo haya utilizado como eje vertebrador de su propio escrito. Según la bien fundada hipótesis de Saverio Desideri, puede tratarse de una obra latina de los siglos IV o V, de autor pagano, rehecha en el siglo IX para "servir como norma de ejercicio político", al modo de un speculum regum. Pero incluso en el caso de que fuera un texto de origen griego medieval - de ahí la atribución a Plutarco-: Juan podría haberlo conocido en la misma Inglaterra, donde hay ejemplos de influencias anteriores de este género, o en Italia, donde residió algún tiempo entre 1147 y 1153 . Recordemos, en apoyo de estas conjeturas, que fue en

\footnotetext{
"La hipótesis de que la Institutio Traicani no fue una invención de Juan de Salisbury se encuentra en el fundamental libro de Max KERNER, Johannes von Salisbury und die logische Struktur seines Policraticus, Wiesbaden, 1977. Vid. también, S. DESIDERI, La 'Institutio Traiani', Génova, 1958, y P. HADOT, "Fürstenspiegel", Reallexikon für Antike und Christertum, 8, 1972, col. 623, citados ambos por M. SENELlaRT, Les arts de gouverner. Du regime médiéval au concept du gouvernement, París, 1995.
} 
Inglaterra, a finales del siglo X, donde algunos autores - Aelfric, Wulfstan, obispo de Londres - expresaron la imagen de los tres órdenes de la sociedad -sacerdotes, guerreros, campesinos-, precisamente a los pocos años de haberse compuesto en Constantinopla las obras de Constantino VII Porfirogéneta, que se organizan de acuerdo con esa tripartición ${ }^{12}$ y que pudieron ser conocidas en Occidente por diversas vías, entre ellas, por ejemplo, los contactos establecidos a consecuencia de la boda del emperador Otón II con la princesa bizantina Teófano. Es cierto, sin embargo, que, casi dos siglos después, Juan de Salisbury no utiliza la imagen trifuncional de la sociedad sino otra, de tipo corporativo y organicista, relativa solamente al orden político. El origen o tradición indoeuropea de todas estas imágenes ha sido bien establecido desde hace tiempo y, además, la que utiliza Juan es una forma secularizada de la metáfora de la Iglesia como cuerpo cuya cabeza es Cristo, por lo que su aceptación era más sencilla ${ }^{13}$.

\section{El PRÍNCIPE EN "Policraticus"}

Tal como Plutarco la concibe, la comunidad política es algo así como un cuerpo que está dotado de vida por el favor divino, actúa al dictado de la suma equidad y se gobierna por lo que podriamos llamar el poder moderador de la razón. Todo aquello que nos instruye y forma en el culto de Dios (no digo "de los dioses" como Plutarco) y nos dicta las ceremonias del culto, hace las veces de alma de este cuerpo de la comunidad política. Es, pues, necesario mirar a los que presiden el sagrado culto como alma de este cuerpo, y venerarlos como tales. Porque, ¿quién se atreverá a dudar que los ministros de la santificación son vicarios del mismo Dios?. Además, así como el alma alcanza la supremacía sobre todo el cuerpo,

\footnotetext{
${ }^{1}$ Sus libros sobre las Ceremonias de la Corte, la manera de administrar el Imperio, y los themas: sus Geoponika sobre el mundo rural, donde se expone una visión trifuncional o tripartita del orden político de la sociedad : 'strateian te kai ierosynen kai georgian'. El De administrando Imperio, de Constantino VII, ha sido editado por G. MORAVCSIK y R.J.H. JENKINS, Washington, 1967. Vid. también. B. BEAUD, Le Savoir et le monarque: le traité sur les nations de l'Empereur byzantin Constantin VII Porphyrogénète. "Annales ESC", 45 (1990), p. 559 y ss.

${ }^{13}$ Para todas estas cuestiones, me remito como referencia más próxima a mi estudio introductorio a la edición de Policraticus citada en la primera nota. Y, especialmente, a la profunda exposición y análisis general que llevó a cabo G. DUBY, Les trois ordres ou l'imaginaire du féodalisme, Paris, 1978. Planteamientos generales en las obras, más antiguas, de G. DưmEzIL, Mito y epopeya. La ideología de las tres funciones en las epopeyas de los pueblos indoeuropeos. Barcelona, 1977, y, Les dieux souverains des Indo-Européens. Paris. 1977.
} 
aquellos a quienes nuestro autor llama "prefectos de la religión” presiden todo el cuerpo de la comunidad política...

El príncipe ocupa en la comunidad política el lugar de la cabeza y se halla sujeto solamente a Dios y a quienes en nombre de él hacen sus veces en la tierra, como en el cuerpo humano la misma cabeza tiene vida y es gobernada por el alma. El Senado ocupa el lugar del corazón, ya que de él proceden los comienzos de los actos buenos y malos. Los jueces y los gobernadores de las provincias reclaman para sí la misión de los ojos, los oídos y la lengua. Los oficiales y soldados se correspoden con las manos. Los que asisten al príncipe de modo estable, se asemejan a los costados. Los recaudadores y mayordomos /'commentarienses'/ pueden ser comparados al vientre y los intestinos. Si éstos se congestionan por una desmesurada avidez y retienen con excesivo empeño lo que han acumulado, engendran innumerables enfermedades sin cura posible, hasta el punto de que esta dolencia puede conllevar la destrucción de todo el cuerpo. Los agricultores se parecen a los pies, que se encuentran continuamente pegados al suelo. Para ellos es especialmente necesaria la atención de la cabeza, ya que tropiezan con muchas dificultades mientras pisan la tierra con el trabajo de su cuerpo, y merecen ser protegidos con tanta o más justa protección cuanto que mantienen de pie, sostienen y hacen moverse a todo el cuerpo. Deja sin esas piezas de los pies a cualquier cuerpo, por robusto que sea, y no podrá caminar por sus propias fuerzas...

Plutarco añade otras muchas cosas de este estilo, que luego desarrollará más ampliamente en un tratado un tanto difuso, para instrucción de lo que es la comunidad política y enseñanza de los magistrados. Expresar todo esto, sílaba por sílaba, es propio de una interpretación servil, que más bien se refiera al estilo que a las intenciones del autor ... pasando por alto lo que corresponde al culto a los ídolos, nos limitaremos a explicar con brevedad la mente de este hombre en la medida en que buscaba que el principe y los cargos de la comunidad política se amoldaran a la práctica de a justicia.

La extensa cita que precede es la introducción mejor y más clara que puede hacerse al pensamiento político organicista y corporativo de Juan de Salisbury, con sus propias palabras $\mathrm{y}$, además, la más breve ${ }^{14}$. Por eso

\footnotetext{
${ }^{14}$ Policraticus, V,2., pp. 347-348. La imagen corporativa se repite muchísimo en los escritos de teoría política desde el siglo XIII pero los autores suelen limitarse a exaltar la función regia - cabeza, alma o corazón- y su primacía en el conjunto del cuerpo, que sin ella no puede ser, y no entran en detalles sobre las partes de éste y sus respectivas funciones. Así, Alfonso X en textos bien conocidos del Espéculo, Fuero Real y Partidas, y otros muchos escritos de la Baja Edad Media y del siglo XVI españoles. Sólo en Partidas II,IX, al tratar de los oficios de Corte, se les caracteriza en general, comparándolos con 'miembros' del cuerpo (cerebro, órganos internos, sentidos exteriores) que sirven al rey-cabeza, pero se menciona a Aristóteles. en sus castigos a Alejandro, como fuente de la que se toman tales imágenes. Cfr. J.L. BERMEJO, Máximas, principios, pp. 91-92, J.A. MARAVALL, Del régimen feudal al régimen corporativo
} 
mismo, mantendré el criterio de exponer utilizando sus mismos términos, siempre que pueda. En los capítulos siguientes de los Libros Quinto y Sexto se va describiendo con desigual extensión e intensidad las características y funciones de cada parte del organismo. Indiquemos, previamente, que la falta de referencias a los sistemas respiratorio, circulatorio y nervioso no responderían sólo a la escasez de conocimientos sobre el cuerpo humano propia de aquel tiempo sino también a la poca sensibilidad de nuestro autor para lo que hoy llamamos sectores económicos de distribución (comercio, servicios): Juan de Salisbury seguía teniendo en la mente la imagen ideal de una sociedad agraria autárquica, a pesar de las novedades que observaba en torno a él como clérigo intelectual, urbano y viajero.

Pero intentó dar respuesta a algunas de ellas, integrándolas en su concepción del orden social, moral y político. Policraticus es una reflexión sobre el poder político a partir de los fundamentos y convicciones teológicas y éticas propias de la renovación intelectual del siglo XII, de un primer "naturalismo" que concibe la acción de los hombres como partícipes en la obra divina, y al orden natural y temporal como desarrollo y expresión positiva - aunque alterada por el mal- del orden sobrenatural y supratemporal, del que depende.

En cada persona, arguye nuestro autor, el cuerpo depende del alma y vive gracias a ella, y el alma, a su vez, de Dios, y participa de la Vida divina tanto por la vía natural de la razón como, especialmente, por la sobrenatural de la gracia, y sólo así, conociendo esta profunda verdad, se garantiza la incolumitas vitae, la salus publica, de cada persona y de la sociedad entera ${ }^{15}$. Pues bien, del mismo modo, en el orden político hay un cuerpo, un organismo vivo con unas funciones diferenciadas y ordenadas desde su cúspide propia, que es la cabeza -el príncipe-, pero ésta, a su vez, sólo puede ejercer rectamente la autonomía que le corresponde en dependencia del alma, y el alma - los sacerdotes- actúa como tal si cumple su función de representar a Dios entre los hombres y mostrar el camino de una

en el pensamiento de Alfonso $X$ y La idea de cuerpo místico en España antes de Erasmo, en "Estudios de Historia del Pensamiento Español", Madrid, 1973, I, pp. 103-156 y 191-214, L. SÁNCHEZ AGESTA, El concepto de Estado en el pensamiento español del siglo XVI, Madrid, 1959, J. M. NiETo SORIA, Fundamentos ideológicos del poder real en Castilla (siglos XIII-XVI), Madrid, 1988, pp. 90-98.

${ }^{15}$ Policraticus, III, 1 
vida recta, individual y colectiva, ordenada a la verdad, al conocimiento de que los hombres son creados por Dios a su imagen y semejanza.

Juan de Salisbury pudo recoger, así, toda la teoría política altomedieval eclesiástica hierocrática, basada en el principio "descendente" del poder (W. Ullmann) y renovarla, integrando en ella las novedades que surgían en su tiempo al difundirse las primeras doctrinas romanistas: reconocimiento de la utilidad pública específica del poder, de la idea de res publica y del príncipe como persona publica, de la lex regia, del principio de salus publica como suprema ley, del delito lesae maiestatis. Al leer Policraticus se puede llegar, así, a dos conclusiones que parecen contradictorias pero que muestran la singularidad de la obra como reflexión propia de su tiempo: por una parte, anuncia algunos de los "conceptos fundadores del Estado moderno" y "marca el umbral de una problemática nueva de la cosa pública" pero, por otra, pretende "neutralizar la retórica del poder absoluto, vuelta a poner en vigor, desde hacía poco, gracias a la renovación del saber jurídico", y su reflexión "permanece unida a una teología que, aunque muestre confianza en la racionalidad del mundo, piensa el gobierno de los hombres en términos de caida, corrupción, coerción necesaria" 16 .

A partir de estas premisas, Policraticus se ocupa, ante todo, del príncipe, cabeza del cuerpo político, para señalar cómo sus deberes principales son la reverencia a Dios y sus representantes, la exigencia de una buena formación y costumbres propias, el rodearse de oficiales capacitados y en fin, saber ganarse el afecto de sus súbditos otorgándoles la protección adecuada. Precisamente escoge a Trajano como modelo por la acumulación de virtudes políticas que se dio en su persona, y completa así las consideraciones sobre el príncipe que desarrolla en el Libro Cuarto a partir de fuentes y ejemplos preferentemente bíblicos, como era tradicional, en especial Deuteronomio, 17,14-20.

He aquí las principales: la consideración del príncipe como 'persona publica', “pública potestad e imagen cierta en la tierra de la Divina Magestad ... Quien resiste a la potestad del príncipe, resiste a la disposición de Dios" $(\mathrm{IV}, 1)^{17}$. Pero se da por supuesta la condición de que el príncipe

\footnotetext{
${ }^{16}$ Citas de M. SEnElLaRT, Les arts de gouverner, pp. 127-145.

${ }^{17}$ Sobre la permanencia y evolución de la idea de origen divino del poder real, de su carácter sacral y de su vinculación religiosa, vid. las consideraciones de J.M. NIETO SORIA, Origen divino, espíritu laico y poder real en la Castilla del siglo XIII, "Anuario de Estudios Medievales", 27/1 (1997), pp. 43-101 y, con carácter más general, Fundamentos ideológicos
} 
“obedece la ley y, conforme a ella, rige al pueblo, del que se estima servidor ... La autoridad del principe se basa en la autoridad de la ley. Que el príncipe se someta a las leyes es en verdad más importante que el poder imperial, de modo que el príncipe no debe considerar para sí lícito lo que se aparte de la equidad de la justicia" $(I V, 1)$. Porque, en definitiva, esa equidad proviene de Dios y "la ley es su intérprete ... Toda ley es un descubrimiento y don de Dios, preceptora de sabios varones, corrección de los excesos de la voluntad, ordenamiento ciudadano y disuasión de cualquier delito" (IV,2). El príncipe tiene tal poder que "está libre de las ataduras de la ley,/pero/ no porque le sea lícito praticar la iniquidad, sino porque debe ser tal que promueva la equidad ... Su voluntad debe tener la fuerza del juicio, y con toda razón debe tener en tales asuntos peso de ley lo que a él le place, ya que su decisión no discrepa del sentido de la equidad" (IV,2). Porque, en definitiva, no está totalmente libre de las leyes, sino sujeto a la ley divina y a la ley de la justicia:

Que salgan ahora los que enjalbegan la faz de los poderosos y susurren, o, si esto les parece poco, proclamen públicamente que el príncipe no está sujeto a la ley y que todo lo que le place, no sólo el establecer el derecho conforme a equidad, sino de cualquier forma, tiene fuerza de ley. Si quieren y se atreven, que pongan fuera de la ley al rey que sustraen de sus ataduras. Yo reafirmo que está obligado por esta ley, no sólo contra el parecer de éstos, sino aunque todo el mundo lo niegue ...No quito, sin embargo, de las manos de los príncipes el poder de dispensar de la ley, sino que pienso que de ninguna manera está a su arbitrio lo que contiene una prohibición o un mandato perpetuos. Sólo en las cosas mudables se admite dispensa del precepto ; y de tal forma, con todo, que por la compensación de la honradez o la utilidad se conserve íntegra la intención de la ley $(\mathrm{IV}, 7)$.

Ésta es la réplica de Juan de Salisbury a los que exaltaban la lex regia, que acababa de redescubrirse, como prerrogativa real ilimitada (quod principi placuit vigorem habet legis). Para nuestro autor, por el contrario, hay una relación indisoluble y jerarquizada entre ley-equidad, poder real y ejercicio de la justicia: el rey está sujeto a la Ley, con mayúscula, pero por encima de las leyes mudables y debe aplicar una y otras, poniendo su poder al servicio del sentido de la equidad, para cumplir su misión principal, que

del poder real, pp. 51-59. 
es hacer justicia a sus súbditos. El príncipe no es, pues, autor de la ley sino su indispensable ejecutor, al aplicar en juicios concretos sus principios abstractos o genéricos. A este cumplimiento de justicia se subordinan las demás funciones, gubernativas, administrativas, militares ... "E sabed que con tres cosas se mantiene el rregno: la primera es la ley, e la segunda es el rey, e la tercera es la justicia", leemos en las Flores de Filosofía, escritas un siglo después en Castilla a partir de fuentes distintas del Policraticus pero imbuídas por el mismo espíritu común ${ }^{18}$.

Junto con el sentido de equidad, el príncipe debe tener la moderación de la sabiduria, para reconducir las irregularidades y errores de todos a la senda de la equidad. Fue muy celebrada y citada la gráfica comparación que hizo nuestro autor: Rex illiteratus quasi asinus coronatus ${ }^{19}$. $\mathrm{Y}$, al mismo tiempo, disponer de fuerza coactiva: "También su escudo es fuerte, pero es escudo de los débiles y repele en favor de los inocentes los dardos de los malvados. No lleva, pues, sin causa la espada con la que derrama sangre sin culpa, sin ser hombre sanguinario, y con frecuencia mata a los hombres sin incurrir en homicidio ni delito... Como la ley persigue los delitos sin odio de la persona, así el príncipe castiga con rectitud a los delincuentes, no por impulso de la ira, sino por disposición de la serena ley" $(I V, 2)$ : se ha señalado a menudo la clara distinción que establece Juan de Salisbury, fue el primero en hacerlo, en este párrafo entre la 'persona pública' y la 'persona privada' del príncipe.

Ahora bien, "todo oficio dependiente de las leyes sagradas es religioso y piadoso". El oficio o ministerio del principado lo es, y guarda con respecto al de los sacerdotes una relación de inferioridad o dependencia "ministerial", pues el principe es "ministro del sacerdocio y ejerce aquel aspecto de los sagrados oficios que parece indigno de las manos del sacerdote". La espada de sangre la posee, como la espiritual, la Iglesia, pero no la usa directamente sino "a través de la mano del príncipe, a quien dio la potestad de la coacción temporal, reservándose para sí la potestad de lo espiritual en la persona de los pontífices". Sin duda, "tiene categoría inferior

\footnotetext{
${ }^{18}$ Flores de Filosofía, cap. 4, p. 20, cit. Por H.O. BIzZARRI, Las colecciones sapienciales castellanas en el proceso de reafirmación del poder monárquico (siglos XIII y XIV), "Cahiers de Lingüistique Hispanique Médiévale", 20 (1995), p. 45.

19Policraticus, IV,6. Sobre la participación en la sabiduría como cualidad necesaria a los reyes, vid. M.A. RODRigUEZ DE LA PEÑA, Imago Sapientiae: los orígenes del ideal sapiencial medieval. "Medievalismo", 7 (Madrid, 1997), pp. 11-39.
} 
aquel /oficio/ que se ejerce en castigo de los delitos y representa de algún modo la imagen del verdugo". Pero esto no es obstáculo para que "si un príncipe constituído en tal dignidad ejerce con fidelidad el ministerio recibido, hay que tributarle tan gran honor y reverencia cuanto prevalece la cabeza sobre todos los miembros del cuerpo" (IV,3). Del mismo modo, leemos en este caso en el Libro Quinto, el príncipe debe respeto a las personas, según alguno de los motivos contenidos "en su naturaleza, o en su profesión, o en su modo de vida, o en su condición social, o en su fortuna", $\mathrm{y}$, muy especialmente, a los sacerdotes y ministros de la Iglesia, porque "Dios es honrado o despreciado, ante todo, en aquellos que administran las leyes divinas, ya que El juzga como propio el honor o el desprecio tributado o inferido a ellos", y también a los lugares de culto, objetos sagrados o cualquier asunto tocante a su ministerio $(\mathrm{V}, 4$ y 5$)$.

Una vez establecida la afirmación general sobre el fundamento del 'ministerio' del príncipe y su preeminencia que sólo cede ante la del sacerdote por la superior dignidad de función de éste, nuestro autor enumera, con acompañamiento de abundantes ejemplos, las condiciones principales para que el príncipe ejerza su oficio con dignidad.

Primero, el saberse servidor de los demás: "sabe que su vida no es para sí, sino para los demás, y se la entrega con ordenada caridad. Debe, por tanto, su ser entero a Dios; lo principal de sí mismo a la patria; mucho a sus parientes y allegados; muy poco, aunque siempre algo, a los extranjeros". Y estas consideraciones valen "tanto para los que tienen a su cargo las cosas espirituales como para los que ejercen la jurisdicción secular". El príncipe es padre y marido para sus súbditos, sin dejarse llevar a favor de su familia natural por el "afecto de la carne ... porque la carne y la sangre no dan a luz por sí mismas el reino ni el sacerdocio, ya que en la generación de uno y otro no puede prevalecer la consideración de los padres sobre los méritos de la virtud, sino los sanos deseos de los súbditos fieles" (IV,3).

Por eso mismo, el príncipe debe ser casto y evitar la avaricia, para que ambos vicios no le aparten del principio anterior y del amor de sus súbditos. Otra cosa es que sea rico: "es conveniente que el rey goce de fortuna, con tal de que no tenga como propia la riqueza del pueblo. No tendrá, pues, como propias las riquezas que posee en nombre ajeno ni serán privados para él los bienes fiscales que reconoce como públicos" (IV,5). Y a la negativa ante los vicios ha de añadir la práctica de determinadas virtudes y disposiciones: "debe tener siempre la ley de Dios ante su pensamiento y su mirada, ser versado en letras y dejarse aconsejar por los letrados (IV,5) 
... aprender el temor de Dios y ser humilde, y conservar la humildad de manera que no quede disminuída la autoridad ... Conserve con cuidado en público el respeto del pueblo por su potestad" (IV,7). Debe conjugar "la moderación en la justicia y clemencia ... para utilidad de la comunidad política", sin caer en desviaciones: "Y no se desvíe a la derecha o a la izquierda" /Deuteronomio, 17,20/:

\begin{abstract}
Desviarse a la derecha es insistir demasiado en las virtudes mismas. Desviarse a la derecha es exceder la moderación al obrar la virtud, que consiste precisamente en la moderación. Toda vehemencia es enemiga de la salvación y en todo exceso hay culpa; y no hay nada peor que el uso inmoderado de las cosas buenas... Desviarse a la izquierda es apartarse o desviarse del camino de la virtud por el despeñadero de los vicios. También se desvía a la izquierda el que es proclive en exceso a la venganza contra las culpas de los que le están sujetos ... Uno y otro camino son desviaciones, pero es más nocivo el que se dirige a la izquierda (IV,8 y 9).
\end{abstract}

En suma, leemos ya en el Libro Quinto, de las costumbres de los príncipes derivan para sus pueblos bienes o males, y el autor completa su reflexión tratando sobre otras varias virtudes: austeridad y sobriedad, desprecio del enriquecimiento, tenacidad en la tarea pues, de nuevo en cita bíblica, donde no hay quien gobierne, el pueblo va a la ruina (Proverbios,11,14) $(\mathrm{V}, 7)$. Páginas antes, al concluir el Libro Cuarto, Juan de Salisbury ha glosado las cuatro virtudes cardinales, que el príncipe ha de practicar para evitar la ira de Dios y combatir los males derivados de las injusticias, las injurias, las contumelias y los engaños: justicia, templanza, prudencia, fortaleza, son como "los cuatro ríos que salen del paraíso de las delicias de Dios para regar toda la tierra y que ésta dé sus deseables frutos a su tiempo" (IV,12). Es notable lo poco que varió en los siglos siguientes el repertorio de consejos y reflexiones morales dirigidos a los príncipes, aunque se ganara en sistematización y claridad expositiva, en función del propio desarrollo de la teoría del poder político y del gobierno: para comprobarlo, basta comparar el contenido de estas páginas de Policraticus con las de autores más recientes, desde el siglo XIII hasta los españoles del $\mathrm{XVII}^{20}$.

\footnotetext{
${ }^{20}$ Sobre los "espejos de principes" me remito, en general, a la obra de M. SENELLART, Les arts de gouverner. Para el ámbito castellano: B. PALACIOS MARTín, El mundo de las idecas políticas en los tratados doctrinales españoles: los "espejos de principes" (1250-1350), en "Europa en los umbrales de la crisis (1250-1350)", Pamplona, 1997, pp. 463-483, M. HARO
} 
Debe entenderse que el mayor premio que puede esperar un príncipe como recompensa de su buen gobierno es tener un largo reinado y ser sucedido por su hijo pues "no hay nada que más deseen los hombres que tener a sus hijos como sucesores de sus bienes", de modo que esta esperanza "es la que con mayor fuerza puede incitarlos /a los príncipes/ a la práctica de la justicia". Pero "no se guarda en absoluto el orden de la caridad cuando el padre pone en los hijos el amor que es debido preferentemente a la patria" $(I V, 11) y$, por otra parte, el derecho hereditario no es consustancial al principado, según leemos en V,6: "Dios lo escoge entre otros, bien por el misterio de su providencia, bien valiéndose de una especie de elección de los sacerdotes, bien por la convergencia de las opiniones de todo el pueblo". En el Antiguo Testamento, "aparece con toda nitidez que no se da ninguna aclamación del pueblo, ninguna relación de consanguinidad o parentesco ... Porque la herencia debe ser transmitida a los parientes tanto de lo que toca a las tierras y predios, como incluso de los cargos públicos. Pero el gobierno del pueblo debe ser confiado a quien Dios ha elegido para ello ... No obstante, no es lícito prescindir, en favor de otros hombres, de la sangre de los príncipes, a quienes por privilegio de la divina promesa y por el derecho del linaje se debe la sucesión propia de los hijos, siempre que, como está prescrito, caminen por las vías justas del Señor".

Es decir, la hereditariedad no se justifica sin más como derecho adquirido e inmutable sino que es una vía válida en cuanto costumbre aceptada y, por lo tanto, manifestación de la providencia divina sobre quién ha de ejercer el principado... "Siempre que" /los príncipes/, como está prescrito, "caminen por las vías justas del Señor. Y si se apartasen un poco del camino recto, no por eso se les debe enseguida desposeer del todo, sino que con un poco de paciencia se corrige la injusticia, mientras no conste con suficiente claridad que se mantienen pertinaces en el mal camino" $(\mathrm{V}, 6)$. En

\footnotetext{
CORTÉs, La imagen del poder real a través de los compendios de castigos castellanos del siglo XIII. Londres, 1996, y, J.M. NIETO SORIA. Les Miroirs de Princes dans I'historiographie espagnole (Couronne de Castille, XIIr'-XV' siecles). Tendances de la recherche. a publicar en "Speculum Principum. Ius Commune Sonderhefte" (Max-Planck Institut für Europäische Rechtgeschichte. Frankfurt). Agradezco al Prof. Nieto su amabilidad al permitirme la consulta de este trabajo, todavía inédito, y facilitarme referencias bibliográficas que me han ayudado dar una forma más completa a estas páginas. Para los autores de los siglos XVI y XVII. J.A Maravall Casesnoves, Teoría española del Estado en el siglo XVII, Madrid, 1944; M.A GALINO CARRILlO, Los tratados sobre educación de príncipes (siglos XVI y XVII), Madrid, 1948; F. Elías de Tejada y Spínola, Historia de la Literatura Política en las Españas. Madrid, 1991, 3 vol., y L. SÁNCHEZ AgESTA, El concepto de Estado, ya citado.
} 
tal caso, "el reinado será transferido de un linaje a otro por razón de las injusticias, las injurias, las contumelias y los diversos engaños" (Eclo. 10,8).

Con estas reflexiones, además, ha puesto las bases previas a su teoría sobre el justo derecho de resistencia al tirano, que incluye su muerte, si es preciso. Pero no nos detendremos ahora en este aspecto, el más conocido entre las doctrinas políticas de nuestro autor.

La descripción de las otras partes del cuerpo político apenas hace mención de su cabeza, salvo en lo referente a las precauciones que ha de tomar para escoger a unos u otros colaboradores y administradores públicos. A Juan de Salisbury le preocupa, sobre todo, la sabiduría de los consejeros que componen el corazón o 'senado', y la honradez y resistencia a la corrupción de los oficiales de la Corte que forman los costados, aunque considera que ésta es un vivero de "personas viciosas /y/ ni siquiera se puede confiar en la vida pasada de nadie, ya que entre los cortesanos es casi imposible conservar la inocencia ... porque para que la virtud quede incólume es necesario apartarse de la vida de los cortesanos ... Un filósofo cortesano es algo verdaderamente monstruoso ... por la sencilla razón de que la Corte descarta la filosofía, y el filósofo no acepta en ningún caso las necedades cortesanas. No debe aplicarse, sin embargo, esta comparación a todas las Cortes, sino sólo a aquéllas que pierden su debido orden por decisión de algún necio" $(\mathrm{V}, 10)$.

Ojos, oídos y lengua son "los gobernadores de las provincias ... que rigen a sus habitantes en la administración de la justicia" (V, 11 a 16). El buen gobierno es, ante todo, hacer justicia, y se trata, por lo tanto, de valorar esta función, basada en la voluntad para el bien, tanto o más que en la aplicación de conocimientos técnicos o medios coactivos, lo que exige una rectitud a toda prueba, garantizada previamente en el juramento, demostrada en la aplicación de los adecuados procedimientos judiciales y procesales y, especialmente, en el alejamiento de toda tentación de extorsión y venalidad, de toda aceptación de sobornos o mal uso del dinero y las riquezas. Nuestro autor considera que, en general, "las riquezas son espinas ... cierran el camino hacia la sabiduría", pero añade prudentemente que "no está el vicio en las cosas sino en su uso, aunque ha prevalecido tanto el reinado del dinero que se llega a no creer en la fidelidad de un juez que rechaza los dones que se le ofrecen" $(\mathrm{V}, 17)$. De modo que también la corrupción 
aparece como el mayor riesgo en el ejercicio de la función del juezgobernador, el que más puede impedir que cumpla bien sus cometidos: que "la provincia viva en paz y tranquilidad... Que los poderosos no causen perjuicio a los más débiles", que no haya "exacciones sin fundamento, actos de violencia, ventas y cauciones hechas por temor y sin determinación de precio"... que no se grave a las gentes "con excesivas concesiones de hospitalidad ... que nadie tenga ganancias o sufra daños injustos", y que se asegure la persecución de los malhechores $(\mathrm{V}, 15)$. .

"Seguiré su esquema" - comienza Juan de Salisbury su Libro Sexto, refiriéndose a Plutarco- "y descenderé con él desde la cabeza de la sociedad hasta sus pies, con esta condición no obstante: que si en esta parte del trabajo les pareciera a los legos en derecho que me muestro un tanto mordaz, no me echen a mí la culpa sino a Plutarco o, mejor, a sí mismos, por no haber querido aprender la regla que profesan y según la cual tienen que vivir". Como en ocasiones anteriores, el autor pretende suavizar sus admoniciones críticas de tipo moral introduciendo algún tipo de excepción o amparándose bajo una autoridad superior para que el rechazo no impida el entendimiento de su mensaje. Éste sigue siendo, al igual que en los dos libros precedentes, de apariencia más bien general y atemporal; a pesar de que hay algunas anécdotas relativas a la época en que vivió Juan de Salisbury o a otras relativamente próximas, lo habitual es que se refiera a autores clásicos, tomando de ellos conceptos aplicables a cualquier situación, aunque el autor tenía en su mente las contemporáneas y, en cierto modo, procuraba darlos respuesta.

Así sucede que, al tratar de las manos del cuerpo político, las describe según el modelo propio del bajo Imperio Romano, como dos militiae, la civil o 'desarmada' de los oficiales o funcionarios públicos, y la 'armada' o castrense. "La mano armada se aplica solamente contra el enemigo, pero la desarmada se extiende también al ciudadano. Y es necesaria la disciplina de ambas, porque en las dos suele hacerse muy patente la malignidad". El príncipe debe controlar ambas, "e incluso más cuidadosamente ha de ser controlada la desarmada, porque, así como los armados están estrictamente obligados a abstenerse de exacciones y rapiñas, los desarmados no sólo eso, sino que también deben rehuir los cohechos" $(\mathrm{VI}, 1)$

Las consideraciones sobre el oficio o 'milicia' civil son breves y se refieren al defecto considerado más habitual y grave de quienes la forman, en especial recaudadores de rentas, que abusan y esquilman "a la luz del día, 
y ni los gobernadores ni sus delegados los reprimen, porque, como suele decirse, el cuervo se congratula de las fechorías del lobo y el juez impío aplaude al servidor de la iniquidad", a pesar del daño que se sigue al príncipe "cuando la tierra es esquilmada por esos ministros de iniquidad y de crimen" (VI,1). El autor detecta la naciente complejidad administrativa que se vivía en su tiempo pero no tiene interés en analizar y comprender sus causas y efectos; se limita a condenas generales de los abusos, utilizando una nomenclatura arcaica, más propia del siglo IV que del XII, porque, hay que recordarlo siempre, el suyo es un libro sobre la moral del poder, en el que se contempla sólo la ley y los hombres, los administradores de poder y los sujetos a ellos.

Por eso mismo, la extensísima descripción del brazo armado tampoco da pie a un estudio sobre la organización de quienes tenían poder militar en su tiempo, sino a una amplia glosa de Vegecio, de modo que en ella encuentre el príncipe las ideas adecuadas para controlar ese brazo armado, esa "profesión tan laudable como necesaria /a la que/ nadie puede vituperar sin faltar al respeto a Dios, por quien ha sido instituída" (VI,5), para el servicio de la religión y el culto a Dios, "no menos que la milicia espiritual ... porque debe obediencia al príncipe y permanente servicio a la comunidad, lealmente y según la voluntad de Dios" (VI,8). Por eso, "no hay diferencia entre que un soldado milite a las órdenes de un creyente o de un infiel, mientras sirva sin violar su propia fe ... Primero debe cumplirse sin mancha con la fidelidad debida a Dios, y luego con la debida al príncipe y a la comunidad" (VI,9). Ahora bien, en una sociedad cristiana, el "recto uso de una ordenada clase militar" consiste en "proteger a la Iglesia, impugnar la perfidia, venerar al sacerdocio, defender al pobre de la injusticia, pacificar a la gente, derramar la sangre por los hermanos y, si fuera necesario, dar la vida" (VI,8). Los militares tienen que realizar ejecutando, según el criterio de Dios y en fidelidad a Dios. Así, son santos los soldados (VI,8). Juan de Salisbury también trató sobre el difícil asunto de la obediencia debida:

\footnotetext{
Así como a los que siguen la vida religiosa no les está bien discutir los mandatos de los prelados (en tanto no vayan contra la ley eterna), sino cumplirlos, así en la milicia no se permite ninguna discusión del soldado respecto a las órdenes del jefe, a no ser que lo que se mande se vea que es manifiestamente contrario al bien común. Porque en este caso sólo obedece el soldado impío e infiel ... Por supuesto, se debe gran respeto al que manda, pero siempre salvando la santidad de la fidelidad ... Hay algunas cosas tan necesarias que no requieren una orden, y otras tan detestables que
} 
ninguna orden las justificaría o las haría permisibles. Las otras cosas intermedias entre ambas, que ni son necesariamente buenas ni malas, quedan a la discreción del que manda, sobre todo si competen ad statım publicum $(\mathrm{VI}, 12)$.

No fue Juan de Salisbury el único autor de su tiempo en ocuparse detalladamente de la moral profesional del guerrero al servicio del poder - pensemos en San Bernardo y su De laude novae militiae-, y en sus reflexiones está implícita la preocupación del pensador eclesiástico sobre cómo justificar moralmente una función que por su misma naturaleza entra en oposición con la ética de la no violencia, y cómo sujetarla a las directrices de la ley y al respeto debido al predominio del sacerdote, que es intérprete superior de ella: los militares están "obligados respecto a la Iglesia por juramento solemne ... Si en cualquier profesión es necesaria la disciplina, en ninguna tanto como en el clero y en la milicia. Pero esta última, que se ejercita menos en espíritu, ha de ser más duramente castigada en el cuerpo" (VI,11). Se trata, en pocas palabras, del problema de la cristianización de la caballería como pauta de vida. Además, esta aproximación conceptual entre ambos órdenes - clero y milicia-, dejando bien clara la superioridad del primero, era más importante a mediados del siglo XII cuando el segundo, en torno al respectivo príncipe o señor, había madurado ya el desarrollo de un tipo de poder - militar y político al mismo tiempo-, distinto al específicamente eclesiástico, que también definía con mayor claridad su campo de acción espiritual y su jurisdicción propia. Nuestro autor se esfuerza en mostrar, a través de una exposición muy genérica, la doble dependencia que sujeta a los bellatores y a la fuerza que administran. De una parte, respecto al príncipe, cabeza de la res publica, imagen de Dios ; de otra, más profunda, respecto a los sacerdotes, alma de la res publica, definidores de su relación con Dios.

En resumen: "el que quisiere ser soldado, aprenda de antemano el arte militar y consolídelo con la práctica y el ejercicio, para que, cuando sea elegido y adscrito al juramento de la milicia, viva útilmente para sí y para la comunidad política y no se convierta, como dice Plutarco, en una mano manca. Con estas palabras termina 'La Educación de Trajano', cuando desciende de la consideración de la función de las manos a los pies" (VI,19).

Pies que, al contrario que las manos, reciben breve atención de nuestro autor puesto que no hay para cada uno de sus oficios códigos morales propios, al menos en lo relativo al orden político, que es lo 
importante en el tratado de Juan de Salisbury. "Se llaman pies a aquellos que ejercen los oficios más humildes, gracias a cuya dedicación pueden andar por la tierra los miembros de toda la comunidad política ... Son tantas estas formas /de oficios/, que la comunidad política ha superado, no ya a los cangrejos de ocho patas, sino a los ciempiés, y ciertamente son innumerables por su multitud, no porque sean por su naturaleza infinitos, sino porque se trata de tan variadas clases que ningún escritor de estos oficios ha dado nunca preceptos especiales para cada uno de ellos". Sólo hay uno común: "que no excedan los límites de la ley y todos contribuyan a la utilidad pública", en recíproca interacción jerarquizada entre "las cosas inferiores" y las "superiores.... de tal manera que mutuamente los unos sean miembros de los otros" (VI,20).

En la visión del poder que expone Juan de Salisbury, reside todo él en el príncipe, como cabeza del cuerpo político o res publica, por voluntad y delegación de Dios, sujeto a la misma ley divina -y por ello bajo control del 'alma' que son los sacerdotes- pero por encima de las humanas. Así se podía conciliar un ámbito de autonomía para la autoridad superior e indiscutible del príncipe en lo temporal, con su sujección a un poder supremo, interpretado en este mundo por el sacerdocio.

El poder del príncipe se ejercía o bien directamente o bien de manera indirecta a través de los miembros del 'cuerpo político' con capacidad de mando - judicial, gubernativo y administrativo, militar-, que, por eso mismo, son 'superiores' a los miembros que carecen de ella por su propia función. No hay en Policraticus ningún concepto o imagen "ascendente" del poder, que entienda a la comunidad política de orden natural no sólo como objeto sino también como sujeto y partícipe del poder, ya sea como un todo o ya a través del ejercicio de las libertades y derechos privativos de cada uno de sus estamentos. La primera solución es propia de algunas sociedades contemporáneas ; la segunda, específica de las medievales, sobre todo a partir del siglo XIII. Sus carencias en este campo, como en el de la comprensión de los 'pies' del cuerpo social y la necesidad de regular la especificidad moral y organizativa de cada oficio, sitúan a Juan de Salisbury en el terreno de esa 'mentalidad pre-gótica' que definiera Huizinga hace más 
de medio siglo ${ }^{21}$, o, dicho en otros términos, anterior a la recepción de la Politica de Aristóteles.

Pero tendría larguísima vida, mucho más allá del siglo XIII, aquella imagen de una comunidad natural e inmutablemente jerarquizada en su orden político, que debería imitar el orden de las abejas, tal como lo describía Virgilio y lo repite con entusiasmo nuestro autor, al glosar el tópico de la vida y costumbre de las abejas como la "más recta y elegante. Felices serían sin duda las ciudades si se dieran a sí mismas esta constitución.. Las comunidades venerables, si siguen con perseverancia los ejemplos de las abejas, progresan hacia la vida por un camino compendioso y expedito" (VI,21). El lector no puede dejar de hacerse alguna pregunta crítica sobre por qué tantos autores de teoría política, de tiempos y culturas tan diferentes y distantes, pero intérpretes y partícipes del poder en definitiva, han puesto tanto empeño en reducir a los gobernados a la condición de insectos y situar a la libertad exclusiva de la naturaleza humana - de la que tanto exigían en otros campos - al mismo nivel que la inevitabilidad del instinto animal ${ }^{22}$.

Juan de Salisbury se mueve entre el reconocimiento teórico de esa libertad, necesaria para aceptar y cumplir humanamente la Ley, y las consecuencias que de ello se derivan, incluso la licitud de acabar con el príncipe tiránico, y, de otra parte, la prudencia intelectual que le exige apuntalar el orden político tal como lo concibe y lo ha descrito, con sus jerarquías inmutables, con sus abusos también: "Los vicios del poder deben ser tolerados, porque en él reside la esperanza de la salud pública, y porque los dispensadores de la salud pública son como el estómago, que distribuye los alimentos en el cuerpo ... Aunque el principado sea remiso en el ejercicio de las virtudes, ha de ser, sin embargo, mantenido. Y lo mismo que las abejas llevan sobre sus espaldas a su rey ${ }^{23}$, así los súbditos, que ya hemos dicho que son como sus pies y miembros, mientras no resulte pernicioso por sus vicios, han de rendirle pleitesía" (VI,24). E inserta nuestro autor el conocido apólogo de la rebeldía de los miembros del cuerpo

\footnotetext{
${ }^{21}$ J. Huizinga, John of Salisbury: A Pre-Gothic Mind, en "Men and Ideas", Nueva York, 1966 (primera edición del artículo en 1933).

${ }^{22}$ J.L. BERMEJO, Máximas, principios, pp. 177-181, desarrolla una interesante glosa sobre el símil político de las abejas en autores castellanos de los siglos XV y XVI.

${ }^{23}$ Es bien sabido que en época de Virgilio, como en la de Juan de Salisbury, no se concebía que hubiera una "abeja reina" sino una "abeja rey", lo que también implica acaso otro aspecto de la concepción mental de la realidad en cuyo comentario no me detendré ahora.
} 
contra el estómago glotón y vago, para reforzar su argumento, aunque no se priva de exponer una y otra vez los abusos, incluso con ejemplos prácticos referidos a la Curia romana, y condenarlos sin paliativos, porque atentan a un buen orden establecido, en definitiva, de modo que la religión permanezca incólume (VI,25).

Por una parte, pues, apoyo moral a los gobernados, carentes de capacidad política, pero sin proponer soluciones prácticas para resistir 0 evitar los abusos del poder: "todo lo que en la comunidad es más humilde se conserva tanto más diligentemente con la atención que le prestan los más altos. Relee atentamente 'La educación de Trajano', de la que más arriba hicimos mención, y encontrarás estas cosas extensamente tratadas ..." $(\mathrm{VI}, 25)$. A lo que se añade la cita bíblica: "Quien cierra su oido al clamor del pobre, cuando clame a Dios no será escuchado" (Prov. 21,13) (VI,27).

Pero, por otra, sumisión al poder, que no depende de la comunidad ni es responsable ante ella sino ante Dios: "por mi parte, creo que hay que servir con toda humildad y reverencia no sólo a los buenos y mesurados, sino también a los malvados; pero hay que hacerlo de acuerdo con las normas de la fidelidad y de forma que, en el mismo culto del poder, se honre a Dios, por quien aquél ha sido instituido" (VI,27) “... Todo lo que implica malicia deliberada contra la cabeza o la totalidad de los miembros es un crimen gravísimo y próximo al sacrilegio" porque el príncipe "es en la tierra una especie de imagen de Dios. Y por eso precisamente se llama crimen de majestad ... Muchas son las cosas que constituyen un crimen de lesa majestad; por ejemplo, el asesinato de un príncipe o de un magistrado, la utilización de armas contra la patria, la deserción del campo de batalla, la incitación a la sedición popular contra la comunidad política", la ayuda al enemigo, o a un condenado por haber cometido tal crimen (VI,25).

Así, Juan de Salisbury, del mismo modo que había glosado antes el principio romanista 'quod principi placuit...', introduce ahora el relativo al crimen de lesa majestad y detalla su castigo y consecuencias para el culpable y para sus hijos, citando incluso el Código de Justiniano. Fue uno de los primeros pensadores eclesiásticos en hacer esto y, en ambos casos, adaptó a las categorías mentales y políticas de su tiempo unas ideas surgidas en otro distinto y para otros fines.

Concluyamos: "por la inocencia del pueblo se aplaca el príncipe, y la inocencia del príncipe reprime los movimientos populares" (VI,29). Pero no hay complementariedad ni recíproca responsabilidad: "Quede siempre en vigor la excelencia de la cabeza, porque en ello consiste la salud de todo el 
cuerpo" (VI,26). Un siglo después, Alfonso X de Castilla expresó la misma idea con otras palabras: el rey, "es mayor sobre todo su regno por quien todos los del regno reçiben dono de Dios en ser una cosa ... El regno lleva nonbre del rey, ca por el rey es dicho regno" ${ }^{24}$, o, incluso "el rey es la ley e el fuero e todo el reino" 25 . Esto no eran declaraciones en pro de la tiranía perversa sino, por el contrario, a favor de la autocracia, legitimada por el pensamiento político de aquella época, que consideraba al rey 'cabeza' o incluso 'alma', sin la cual la misma existencia del cuerpo político no era posible. Pero Alfonso X era un príncipe en ejercicio; de Juan de Salisbury y de los demás autores teóricos podía tomar esos elevados principios que, junto con otros, legitimaban su poder, aprender pautas generales de comportamiento moral, degustar gran cantidad de buenos consejos y mirarse en el espejo de los ejemplos del pasado. Pero nunca le dirían - nunca lo hicieron- cómo organizar institucionalmente la comunidad política, cómo ejercer y compartir el poder político en el seno de una sociedad estamental con otros poderes establecidos, ni como mantener o modificar la constitución política de la sociedad misma en relación con los cambios profundos de sus estructuras y valores mentales y materiales.

\section{RÉSUMÉ}

Cet étude établit quelques comparations entre l'usage de la "Institutio Trajani" dans le "Policraticus" de Jean de Salisbury et dans la "Primera Crónica General" d'Alphonse X le Sage, roi de Castille. Après quoi, l'auteur développe quelques considérations sur l'existence réelle de l'"Institutio Trajani" et il reflechit sur la théorie politique du "Policraticus" en ce qui concerne le prince, la légitimation de son "ministerium", les limites de son pouvoir, les vertus qu'il doit posséder, les voies de transmission du pouvoir et le rôle des autres titulaires du pouvoir politique et militaire qui agissent au sein du corps social au nom de l'autorité supérieure du prince.

\footnotetext{
${ }^{24}$ Alfonso X, Especulo, II, 1 y 2, cit. B. GonzÁlez Alonso, Poder regio, Cortes y régimen político en la Castilla bajomedieval (1252-1474), en "Las Cortes de Castilla y León en la Edad Media", Valladolid, 1988, II, p. 208.

${ }_{25}^{25}$ General Estoria, II, ii, 253b 14-15, cit. P. LineHAn, History and the Historians of Medieval Spain, Oxford, 1993, p. 491.
} 


\section{SUMMARY}

This study establishes some comparations between the use of the "Institutio Trajani" in the "Policraticus" of John of Salisbury and the "Primera Crónica General" of Alfonso X of Castile. Following, some comsidetations are made about the real existence of the "Institutio Trajani" and reflections are made on the political theory of the "Policraticus", in what concerns the prince, the virtues that he must have, the ways of transmission of the power and on the roles of other owners of politic or military power that plays their office on the society in the name of the superior authority of the prince. 